\title{
Evaluations of Gastric Acid Pocket Using Novel Vertical 8-Channel pH Monitoring System and Effects of Acid Secretion Inhibitors
}

\author{
Shohei Sumi, ${ }^{1}$ Norihisa Ishimura, ${ }^{1 *}$ Hironobu Mikami, ${ }^{1}$ Eiko Okimoto, ${ }^{1}$ Yuji Tamagawa, ${ }^{1}$ Tsuyoshi Mishiro, ${ }^{1}$ Yoshikazu Kinoshita, ${ }^{1,2}$ \\ and Shunji Ishihara' \\ ${ }^{1}$ Department of Internal Medicine II, Shimane University Faculty of Medicine, Izumo, Japan; and ${ }^{2}$ Department of Medicine, Steel Memorial \\ Hirohata Hospital, Himeji, Japan
}

\begin{abstract}
Background/Aims
The gastric acid pocket has an important role in gastroesophageal reflux disease development. In this study, we utilized a novel 8-channel pH monitoring system with sensor intervals of $1 \mathrm{~cm}$ on the vertical axis for evaluation of postprandial gastric acid pocket in healthy Japanese adults, as well as the effects of vonoprazan and rabeprazole.

\section{Methods}

Twelve healthy volunteers without Helicobacter pylori infection were enrolled. A catheter was inserted transnasally and positioned under $X$-ray guidance, then postprandial acid pocket formation was monitored over time in a sitting position. Thereafter, acid pocket changes were assessed following administration of vonoprazan $(20 \mathrm{mg})$ or rabeprazole $(20 \mathrm{mg})$.

\section{Results}

The gastric acid pocket was successfully measured by use of the present system in 10 cases, while failure occurred in 2 because of inappropriate catheter positioning. Observed acid pockets were visualized with a mean length of $2.2 \pm 0.4$ channels on the top layer of food contents approximately 20 minutes after finishing a meal. There were some variations for lasting time of the acid pocket. Complete elimination within 3 hours after administration of vonoprazan was noted in all cases. Likewise, following administration of rabeprazole, the acid pocket was eliminated in 7 cases, while acidity was reduced though the pocket remained observable in 3.
\end{abstract}

\section{Conclusions}

Gastric acid pocket observations were possible using our novel vertical 8-channel sensor catheter. The present findings showed that vonoprazan strongly suppressed acid secretion within a short period, suggesting its effectiveness for gastroesophageal reflux disease treatment.

(J Neurogastroenterol Motil 2021;27:370-376)

\section{Key Words}

Gastric acid; Gastroesophageal reflux; Potassium-competitive acid blocker; Proton pump inhibitors

Received: May 22, 2020 Revised: None Accepted: October 24, 2020

@ This is an Open Access article distributed under the terms of the Creative Commons Attribution Non-Commercial License (http://creativecommons. org/licenses/by-nc/4.0) which permits unrestricted non-commercial use, distribution, and reproduction in any medium, provided the original work is properly cited.

*Correspondence: Norihisa Ishimura, MD, PhD

Department of Internal Medicine II, Shimane University Faculty of Medicine, 89-1 Enya-cho, Izumo, Shimane 693-8501, Japan Tel: +81-853-20-2190, Fax: +81-853-20-2187, E-mail: ishimura@med.shimane-u.ac.jp 


\section{Introduction}

Gastroesophageal reflux disease (GERD) is characterized by the presence of reflux symptoms, such as heartburn and regurgitation, and/or esophageal mucosal injury caused by reflux of gastric contents into the esophagus. ${ }^{1,2}$ In recent decades, the prevalence of GERD has been increasing in Japan, likely due to the westernization of eating habits, as well as decreased Helicobacter pylori infection rates and increased gastric acid secretion in the general population. ${ }^{3-5}$ To date, it is widely accepted that transient lower esophageal sphincter relaxation (TLESR) is the main mechanism of acid reflux in patients with GERD as well as healthy individuals. ${ }^{6,7}$ TLESR is triggered by gastric distention and thus occurs more frequently after meal ingestion. Although the majority of gastroesophageal reflux episodes occur during the postprandial period, ${ }^{8}$ that finding is paradoxical, because intragastric acidity is rapidly and markedly reduced by the buffering effect of food during the period. In 2001, Fletcher et al ${ }^{9}$ were the first to report the presence of an unbuffered acidic region in the proximal stomach during the postprandial period. This acid layer on top of the ingested meal, which escapes the buffering effect and is referred to as a gastric acid pocket, is now considered to be an important mechanism of GERD. ${ }^{8,10,11}$ TLESR can cause reflux of the highly acidic contents of the acid pocket into the esophagus during the postprandial period, especially in GERD patients with hiatal hernia. ${ }^{10,11}$ However, details regarding the acid pocket in Japanese patients with GERD as well as healthy adults remain to be fully elucidated.

Proton pump inhibitors (PPIs) are often used as first-line treatment for $\mathrm{GERD}^{2}$ and have been shown to reduce the size of the acid pocket. ${ }^{12,13}$ Recently, vonoprazan, a new potassium-competitive acid blocker, has been approved as a treatment option for GERD in Japan. ${ }^{14}$ This drug has been shown to provide faster, steadier, and more potent acid reducing effects as compared to conventional PPIs. ${ }^{15,16}$ However, no known report regarding the effects of vonoprazan on the acid pocket have been presented.

In most previous studies of gastric acid pockets, measurements were performed by use of a pull-through technique with dual $\mathrm{pH}$ sensors. ${ }^{9,13,17}$ However, such a technique only provides information during a very brief period of time and changes over time cannot be observed. To address this issue, we developed a novel catheter equipped with 8 vertically arrayed $\mathrm{pH}$ sensors. The aim of this study is to evaluate the gastric acid pocket in healthy subjects during the postprandial period with this $\mathrm{pH}$ sensor catheter. In addition, we sought to determine postprandial changes of the gastric acid pocket following administration of vonoprazan as compared to rabeprazole, a conventional PPI, with our system.

\section{Materials and Methods}

\section{Enrolled Subjects}

Twelve healthy adult volunteers were recruited ( 7 males, 5 females; mean age 24.0 \pm 2.6 years, range 21-32 years; mean body mass index $20.7 \pm 1.9 \mathrm{~kg} / \mathrm{m}^{2}$ ). All subjects were free of gastrointestinal symptoms. In addition, none had a previous history of upper gastrointestinal surgery, or were taking any drugs that might influence gastrointestinal motility or acid secretion. Each had negative results in a urine antibody test for $H$. pylori and those who had received $H$. pylori eradication therapy at any time were excluded. The protocol was approved by the Ethical Committee of Shimane University Faculty of Medicine (Approval No. 2392). Written informed consent was obtained from the enrolled subjects and the study was carried out in accordance with the principles of the Helsinki Declaration.

\section{Catheter Equipment}

We developed a novel $\mathrm{pH}$ sensor catheter equipped with 8 vertically arrayed $\mathrm{pH}$ sensors in cooperation with Star Medical, Inc (Tokyo, Japan). This flexible catheter measures $2.35 \mathrm{~mm}$ in diameter and is equipped with $8 \mathrm{pH}$ electrodes along the distal end (Fig. 1). The electrodes are arranged at intervals of $1 \mathrm{~cm}$ on the

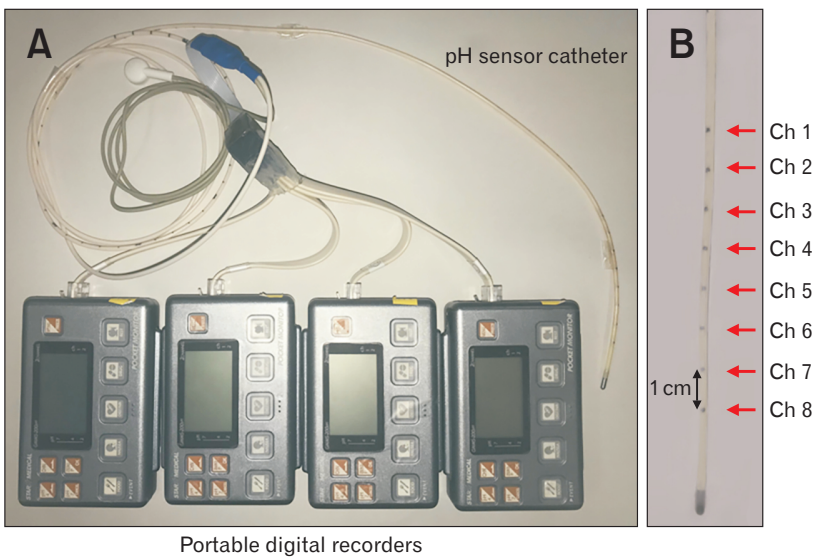

Figure 1. Novel $\mathrm{pH}$ sensor catheter equipped with 8 vertically arrayed $\mathrm{pH}$ sensors (red arrows) used to assess postprandial gastric acid pocket. The sensors are arranged at intervals of $1 \mathrm{~cm}$ on the vertical axis and $\mathrm{pH}$ is measured within a width of $7 \mathrm{~cm}$. The $\mathrm{pH}$ data from the 8 channels can be simultaneously recorded by connecting to 4 portable digital recorders. 
vertical axis and $\mathrm{pH}$ can be determined within a span of $7 \mathrm{~cm}$. This multi-channel $\mathrm{pH}$ sensor catheter has been approved for medical use and is reusable. Eight-channel $\mathrm{pH}$ data can be simultaneously recorded by connecting the catheter to 4 portable digital recorders (Pocket Monitor GMMS-200pH; Star Medical, Inc). Prior to performing the present examinations, the probe was calibrated at room temperature using $\mathrm{pH} 4.0$ and 7.0 buffer solutions.

After providing nasal anesthesia with xylocaine, the catheter was inserted transnasally into the esophagus and positioning was confirmed with fluoroscopic imaging to ensure that the sensor straddled the gastric fluid surface (Fig. 2). The external portion was tightly fixed to the cheek at a point $2 \mathrm{~cm}$ outside the nostril, then
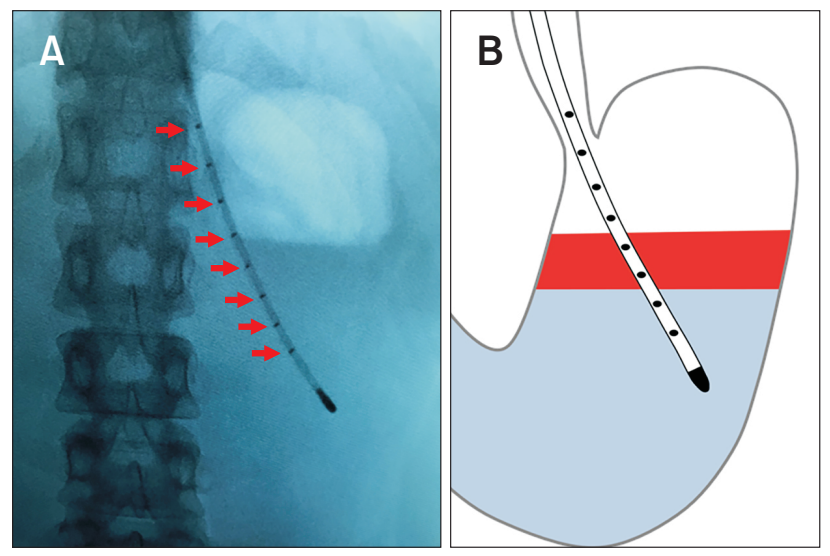

Figure 2. Positioning of 8-channel $\mathrm{pH}$ sensor catheter. (A) Fluoroscopic image and (B) schematic illustration showing 8-channel $\mathrm{pH}$ sensor catheter after insertion. The catheter was inserted transnasally into the esophagus and the position confirmed with fluoroscopic imaging so that the sensor straddled the gastric fluid surface. In the present study, catheter positioning was thoroughly checked before and after ingesting meals using X-ray imaging. hung on an ear and attached to the skin of the neck with surgical tape. The subjects were instructed to remain in the same seated position without deep breathing during the observation period, and the catheter position was thoroughly checked before and after the meal by X-ray imaging.

\section{Study Protocol}

The enrolled subjects participated in 2 study sessions (Fig. 3). All study sessions were performed after an overnight fast. For the first session (Fig. 3A) the $\mathrm{pH}$ sensor catheter was placed transnasally at $8 \mathrm{AM}$ and $\mathrm{pH}$ measuring was started. Starting from 9 $\mathrm{AM}$, the subject consumed a standardized meal, consisting of fried noodles (556 kcal; protein 9.4 g, fat 20.9 g, and carbohydrate $82.6 \mathrm{~g}$ ) and stew (167 kcal; protein $5.9 \mathrm{~g}$, lipid $7.1 \mathrm{~g}$, and carbohydrate $19.7 \mathrm{~g}$ ), and $\mathrm{pH}$ measurements were continued for 3 hours (period 1). Vonoprazan at $20 \mathrm{mg}$ was given at $12 \mathrm{PM}$. At $3 \mathrm{PM}$, the subjects consumed the same standardized meal and then the catheter was removed at $6 \mathrm{PM}$ after 3 hours of measurements (period 2).

PPIs are known to be slow to achieve steady-state inhibition of gastric acid secretion, typically requiring 2 days to 3 days to reach a therapeutic range. ${ }^{16}$ Therefore, in the second study session (Fig. 3B), rabeprazole was administered for 2 days prior to performing $\mathrm{pH}$ measurements. On the day of starting those measurements, the subject consumed breakfast at $7 \mathrm{AM}$ and was given rabeprazole at $20 \mathrm{mg}$ at 7:30 AM. The catheter was inserted at 10:30 AM and the standardized meal noted above was given 1:30 PM. After 3 hours of measurements (period 3), the catheter was removed. There was a washout period of at least 2 weeks between the study sessions. All sessions and testing were conducted by the same experienced investigator (S.S.).

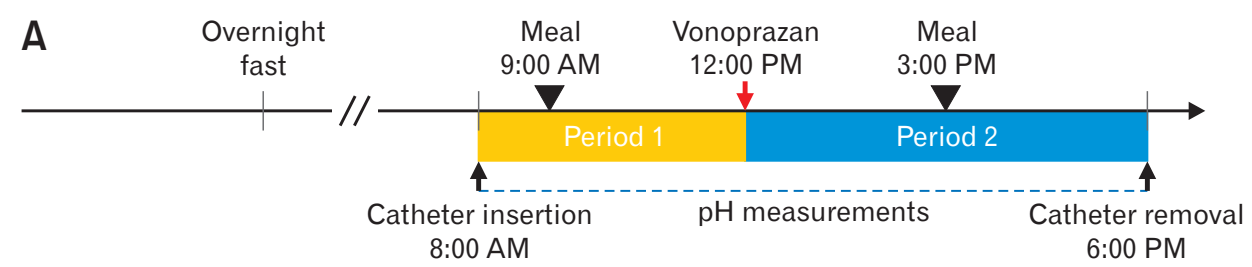

B

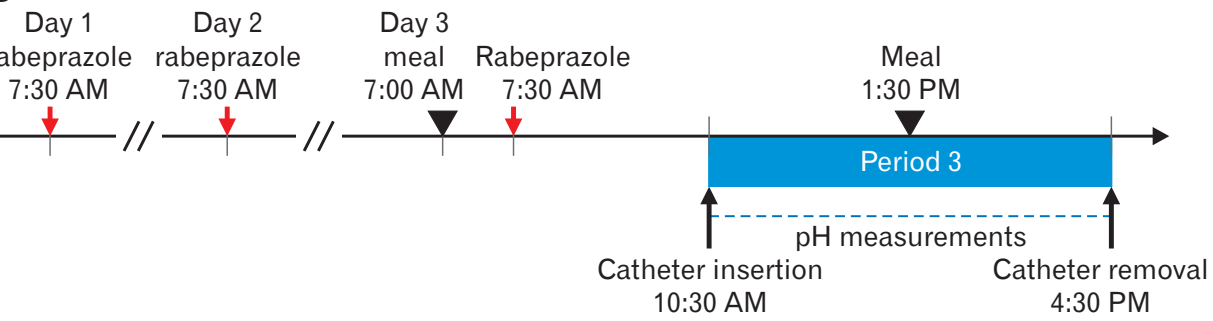

Figure 3. Study protocol. All sessions were performed after an overnight fast. (A) Session 1: postprandial gastric acid pocket (period 1: yellow bar) and the effects of vonoprazan on the pocket (period 2: blue bar) were assessed. (B) Session 2: the effects of rabeprazole on the gastric acid pocket (period 3: blue bar) were assessed. Rabeprazole was administered for 2 days prior to each session. There was a washout period of at least 2 weeks between the sessions. 


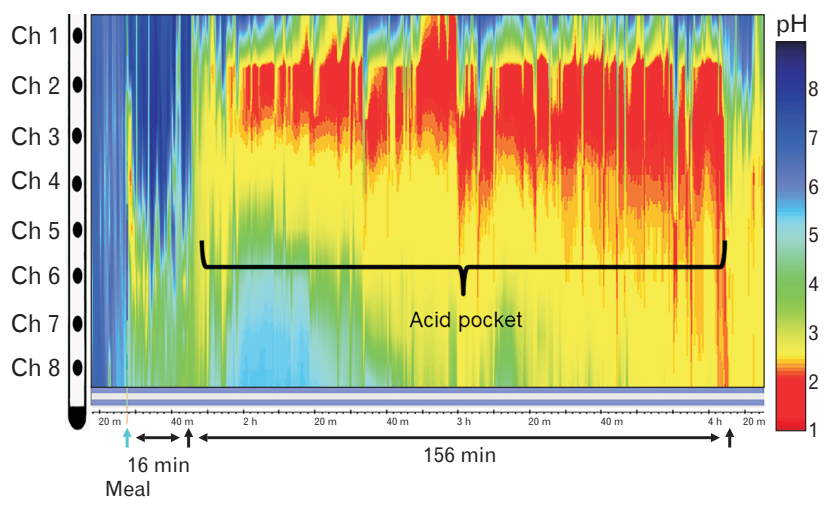

Figure 4. Representative image of postprandial gastric acid pocket. The vertical axis shows the number of $\mathrm{pH}$ sensor electrodes attached to the catheter (channel 1, proximal end, to channel 8, distal end). Horizontal axis shows time and $\mathrm{pH}$ metry is displayed by color surface contour plots.

Table 1. Gastric Acid Pocket Characteristics in Enrolled Subjects ( $\mathrm{n}=10)$

\begin{tabular}{lc}
\hline \multicolumn{1}{c}{ Characteristic } & $\mathrm{n}(\%)$ or mean $\pm \mathrm{SD}$ \\
\hline Detection of acid pocket $(\%)$ & $10(100)$ \\
Length (No. of channels) & $2.2 \pm 0.4$ \\
Appearance time (min) & $19.4 \pm 6.8$ \\
Lasting time (min) & $145.5 \pm 17.9$ \\
Mean acid pocket $\mathrm{pH}$ & $2.4 \pm 0.4$ \\
\hline
\end{tabular}

\section{Data Methods}

Recorded data were analyzed using computer software (Eight Star; Star Medical, Inc). The acid pocket was defined as the distinct region just below the esophago-gastric junction in the proximal stomach, which is clearly more acidic $(\mathrm{pH}<4)$ than the other parts of the esophagus and stomach. ${ }^{8}$ To assess its characteristics, the length, appearance time, lasting time, and mean $\mathrm{pH}$ of the most acidic channel were evaluated in each subject. The length of the acid pocket was expressed by positive numbers of $\mathrm{pH}$ channels. For example, 2 positive channels in the acid pocket indicated a range of $1 \mathrm{~cm}$ to $3 \mathrm{~cm}$ because of the spacing between the $\mathrm{pH}$ sensors. In addition, the effects of vonoprazan and rabeprazole on acid pocket formation were assessed. Values are expressed as the mean $\pm \mathrm{SD}$. Statistical analyses were performed using Fisher's exact test, with $P<0.05$ considered to indicate statistical significance. All statistical analyses were performed using the SPSS statistical analysis software package for PC, version 22.0 (Chicago, IL, USA).

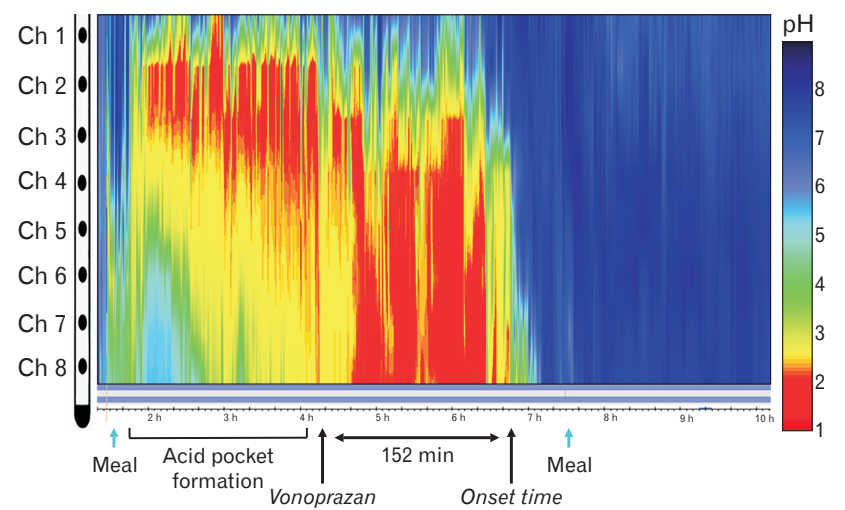

Figure 5. Representative image of postprandial gastric acid pocket after administration of vonoprazan. The acid pocket was completely eliminated following administration in all cases.

\section{Results}

All subjects completed the first study session, though the acid pocket was not appropriately measured in 2 due to catheter position, thus they were excluded. The remaining 10 subjects proceeded to the second study session and all completed the testing. No apparent hiatal hernia was shown by X-ray imaging in any of the subjects. There were no adverse events during any of the sessions.

In the first study session, length, appearance time, lasting time, and average $\mathrm{pH}$ were assessed for postprandial acid pockets in the subjects (Fig. 3, period 1). In Figure 4, a representative image of a postprandial acid pocket is shown, in which the vertical axis shows the electrodes as part of the $\mathrm{pH}$ sensor catheter (channel 1, proximal end, to channel 8, distal end), while the horizontal axis shows time and $\mathrm{pH}$ is displayed by $\mathrm{pH}$ metry color surface contour plots. In this representative case, at 16 minutes after completion of a meal, the gastric acid pocket, with a $\mathrm{pH}$ level of 2 or less, was clearly visualized, and shown to be located at around channels 2 and 3 . The lasting time of this acid pocket was 156 minutes and the length gradually broadened. An acid pocket was observed in all 10 cases that were appropriately measured, with a mean length of $2.2 \pm$ 0.4 channels. The mean appearance time of an acid pocket after completion of a meal was $19.4 \pm 6.8$ minutes, mean lasting time was $145.5 \pm 17.9$ minutes, and mean $\mathrm{pH}$ was $2.4 \pm 0.4$ (Table 1 ).

Next, the effects of vonoprazan on postprandial gastric acid pocket development was evaluated (Fig. 3, period 2). A representative case is shown in Figure 5, in which an acid suppression effect began to appear approximately 152 minutes after administration, while the $\mathrm{pH}$ increased to approximately 7 or 8 after the second meal and no subsequent acid pocket formation was seen. The acid 
A

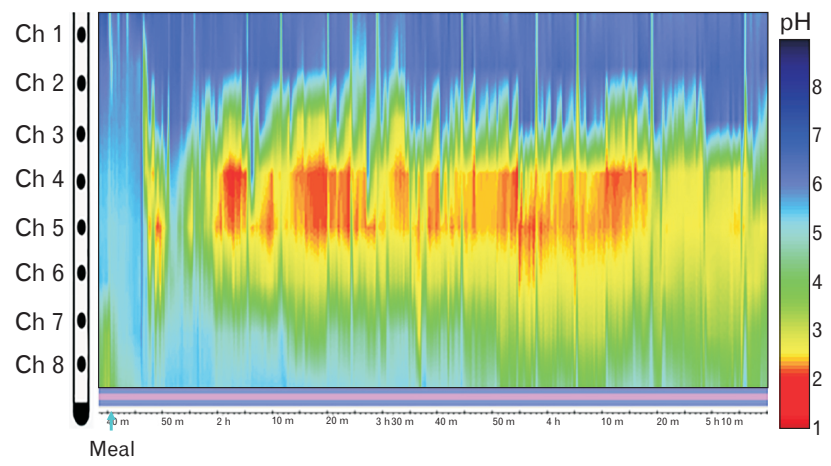

B

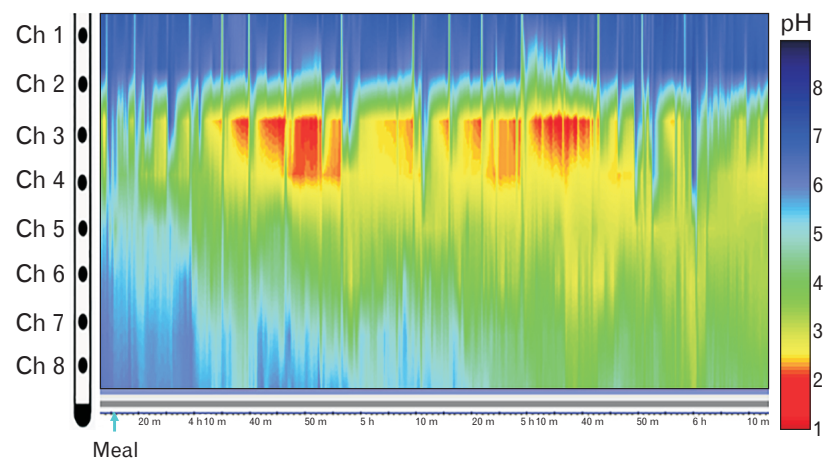

Figure 6. Representative image of postprandial gastric acid pocket after administration of rabeprazole in a subject with remaining the acid pocket. The length was reduced and mean $\mathrm{pH}$ was greater as compared to that before administration (period 1).

Table 2. Effects of Rabeprazole on Gastric Acid Pocket in Subjects With Remaining the Acid Pocket ( $\mathrm{n}=3$ )

\begin{tabular}{lcc}
\hline \multicolumn{1}{c}{ Characteristic } & $\begin{array}{c}\text { Before administration } \\
\text { (period 1) }\end{array}$ & $\begin{array}{c}\text { After administration } \\
\text { (period 3) }\end{array}$ \\
\hline Length (No. of channels) & 2 & 1 \\
Appearance time (min) & $10.7 \pm 4.6$ & $25.3 \pm 9.0$ \\
Lasting time (min) & $154.0 \pm 5.3$ & $102.7 \pm 61.2$ \\
Mean acid pocket $\mathrm{pH}$ & $2.3 \pm 0.2$ & $3.3 \pm 0.4$ \\
\hline
\end{tabular}

Values are presented as $\mathrm{n}$ or mean $\pm \mathrm{SD}$.

pocket was completely eliminated in all cases after administration of vonoprazan. The mean onset time for apparent acid inhibition by vonoprazan was $133.9 \pm 34.2$ minutes. In addition, the mean $\mathrm{pH}$ after administration was $7.6 \pm 0.4$, which was neutralized within 3 hours in all cases.

Finally, the effects of rabeprazole on postprandial gastric acid pocket formation was evaluated (Fig. 3, period 3). Similar to treatment with vonoprazan, the acid pocket was eliminated in 7 of 10 cases. In the 3 cases with a remaining postprandial acid pocket, the length was reduced and mean $\mathrm{pH}$ was greater as compared to that before administration (Fig. 6 and Table 2). These results suggest that an acid pocket in the present subjects had a higher incidence of elimination with vonoprazan as compared to rabeprazole, though there was no significant difference between those administrations $(P=0.105)$.

\section{Discussion}

In the present study, formation of a gastric acid pocket in healthy Japanese adults without $H$. pylori infection was revealed using our novel 8-channel $\mathrm{pH}$ sensor catheter. Although measure- ments of gastric acid pockets performed using a pull-through method with a dual sensor catheter have been presented in previous studies, ${ }^{9,18,19}$ those noted difficulty with observing changes over time. Recently, multi-pH catheters with 4 to 12 sensors have been uniquely developed for acid pocket assessment, ${ }^{20-22}$ though unfortunately not available in Japan. We previously developed a $\mathrm{pH}$ sensor catheter equipped with $8 \mathrm{pH}$ sensors radially arrayed on its surface to clarify radial asymmetrical acid exposure in the distal esophagus and used that to investigate acid exposure time in different portions of the radial walls of the esophagus in patients with GERD. ${ }^{23}$ With that device, acid exposure was found to be predominant on the right wall of the distal esophagus in patients with reflux esophagitis, consistent with endoscopic findings. ${ }^{24,25}$ Based on those studies, we recently developed a novel $\mathrm{pH}$ sensor catheter equipped with 8 vertically arrayed $\mathrm{pH}$ sensors that can be connected to commercially available portable digital recorders. The catheter is $2.35 \mathrm{~mm}$ in diameter and was safely inserted transnasally without pain in all of the present subjects. In addition, as compared to the pull-through technique, visualization of changes in the acid pocket over time was easily performed with this system by viewing the color surface contour plots of the $\mathrm{pH}$ metry.

The gastric acid pocket forms due to secretion of acid from parietal cells located in secretory glands in the proximal stomach. That secretion is affected by various factors, including ethnicity, gender, age, and $H$. pylori infection, with the latter a major cause of gastric mucosal atrophy and reduced secretion. Indeed, acid pocket attenuation has been found in $H$. pylori-infected subjects, ${ }^{26}$ which is consistent with the negative association between that and GERD. ${ }^{27}$ In addition, gastric acid secretion varies among ethnicities, with that in subjects in Japan reported to be lower as compared to Europeans and North Americans, though an increasing trend from 1970 to 
1990 Japanese adults has been noted. ${ }^{5,28,29}$ Those findings suggest that the characteristics of gastric acid pocket formation may be different between Japanese and Western populations. Interestingly, the present results showed that the mean $\mathrm{pH}$ (2.4) of the acid pocket at the highest acidity channel tended to be greater than that noted in previous studies conducted in Western countries. ${ }^{9,30}$ Recently, Wu et $\mathrm{al}^{18}$ investigated postprandial gastric acid pocket development in healthy subjects and GERD patients in China using pull-through $\mathrm{pH}$ monitoring, and the results regarding appearance time, length, and mean $\mathrm{pH}$ of the pocket were similar to those in our study, suggesting that the present approach was consistently and appropriately conducted.

This study is the first known to show the effects of vonoprazan on the gastric acid pocket. This drug has been consistently found to provide quicker and stronger acid inhibition than PPIs, ${ }^{16}$ while the present results indicate that the postprandial acid pocket was completely eliminated and gastric $\mathrm{pH}$ neutralized within 3 hours after a single administration of a standard dose $(20 \mathrm{mg})$. In contrast, the acid pocket remained observable in 3 of 10 subjects for 3 days following rabeprazole administration. Although PPIs remain as firstline treatment for GERD, ${ }^{1,2}$ up to $40 \%$ of those patients remain symptomatic despite continuous PPI use. ${ }^{31}$ Other disadvantages of PPIs include several days before reaching the maximal effect ${ }^{32}$ and GERD symptoms are not sufficiently relieved after the first dose in two-thirds of administered patients due to the slow onset of action. In addition, accumulating evidence suggests that longterm PPI administration is associated with increased risk of enteric infection, Clostridium difficile-associated diarrhea, and osteoporotic fractures. ${ }^{33}$ In the present study, the acid pocket was completely eliminated after the initial dose of vonoprazan within a short period. Consistent with our results, other recent report has found that ondemand therapy using vonoprazan $(20 \mathrm{mg})$ is an effective alternative maintenance therapy for mild reflux esophagitis. Additionally, it has been suggested that there is no significant difference in overall symptomatic relapse rate in patients with reflux esophagitis undergoing on-demand therapy with vonoprazan or maintenance therapy with a PPI. ${ }^{34}$ The acid pocket is now recognized as an important source of postprandial acid in GERD cases and represents a unique therapeutic target. ${ }^{10,18,21,22}$ Accordingly, on-demand therapy using vonoprazan may provide effective treatment for GERD symptoms during the postprandial period.

The present study has some limitations, including a limited number of subjects and non-inclusion of patients with GERD. It is difficult to directly compare the effects of vonoprazan and rabeprazole on the acid pockets due to the different mechanisms for acid inhibition. Additionally, 2 subjects were subsequently excluded because of inappropriate catheter positioning. With our method, the catheter is not fixed to the esophagus using hemostatic metal clips to reduce the burden caused by endoscopy, ${ }^{20,22}$ thus vertical movement of the catheter may have influenced the accuracy of obtained data regarding the gastric acid pocket. A future study that includes GERD patients with and without hiatal hernia is needed to clarify whether formation of a gastric acid pocket differs as compared to healthy subjects.

In summary, we successfully examined postprandial gastric acid pocket formation in healthy adults in Japan using our novel vertically arrayed 8-channel $\mathrm{pH}$ sensor catheter. Acid pocket development was strikingly suppressed following administration of vonoprazan or rabeprazole. Moreover, a single administration of vonoprazan completely eliminated the acid pocket within a short period, suggesting its effectiveness as treatment for GERD.

\section{Financial support: None.}

Conflicts of interest: Norihisa Ishimura has received research funding from EA Pharma Co, Ltd, Daiichi-Sankyo Co, Ltd, Otsuka Pharmaceutical Co, Ltd; Shunji Ishihara has received research funding from Takeda Pharmaceutical Co, Ltd, Astellas Pharma Inc, EA Pharma Co, Ltd, Janssen Pharmaceutical K.K., ZERIA Pharmaceutical Co, Ltd, and lecture fees from Takeda Pharmaceutical Co, Ltd; Yoshikazu Kinoshita has received research funding from EA Pharma Co, Ltd, ZERIA Pharmaceutical Co, Ltd, and honorarium from EA Pharma Co, Ltd, Astellas Pharma Inc, AstraZeneca K.K., Mylan N.V., ZERIA Pharmaceutical Co, Ltd, Otsuka Pharmaceutical Co, Ltd, Takeda Pharmaceutical Co, Ltd, and Daiichi-Sankyo Co, Ltd. Shohei Sumi, Hironobu Mikami, Eiko Okimoto, Yuji Tamagawa, and Tsuyoshi Mishiro have no conflict of interest.

Author contributions: Shohei Sumi, Norihisa Ishimura, and Yoshikazu Kinoshita designed the study; Shohei Sumi, Hironobu Mikami, and Eiko Okimoto collected the data; Shohei Sumi and Yuji Tamagawa analyzed the data and wrote the draft; and Norihisa Ishimura, Tsuyoshi Mishiro, and Shunji Ishihara made critical revisions. All authors reviewed and approved the final version of the article before submission.

\section{References}

1. Gyawali CP, Kahrilas PJ, Savarino E, et al. Modern diagnosis of GERD: the Lyon Consensus. Gut 2018;67:1351-1362. 
2. Iwakiri K, Kinoshita Y, Habu Y, et al. Evidence-based clinical practice guidelines for gastroesophageal reflux disease 2015. J Gastroenterol 2016;51:751-767.

3. Fujiwara Y, Arakawa T. Epidemiology and clinical characteristics of GERD in the Japanese population. J Gastroenterol 2009;44:518-534.

4. Kamada T, Haruma K, Ito M, et al. Time trends in Helicobacter pylori infection and atrophic gastritis over 40 years in Japan. Helicobacter 2015;20:192-198.

5. Kinoshita Y, Kawanami C, Kishi K, Nakata H, Seino Y, Chiba T. Helicobacter pylori independent chronological change in gastric acid secretion in the Japanese. Gut 1997;41:452-458.

6. Iwakiri K, Kawami N, Sano H, et al. Mechanisms of excessive esophageal acid exposure in patients with reflux esophagitis. Dig Dis Sci 2009;54:1686-1692.

7. Mittal RK, McCallum RW. Characteristics and frequency of transient relaxations of the lower esophageal sphincter in patients with reflux esophagitis. Gastroenterology 1988;95:593-599.

8. Herbella FA, Vicentine FP, Silva LC, Patti MG. Postprandial proximal gastric acid pocket and gastroesophageal reflux disease. Dis Esophagus 2012;25:652-655.

9. Fletcher J, Wirz A, Young J, Vallance R, McColl KE. Unbuffered highly acidic gastric juice exists at the gastroesophageal junction after a meal. Gastroenterology 2001;121:775-783.

10. Mitchell DR, Derakhshan MH, Robertson EV, McColl KE. The role of the acid pocket in gastroesophageal reflux disease. J Clin Gastroenterol 2016;50:111-119.

11. Kahrilas PJ, McColl K, Fox M, et al. The acid pocket: a target for treatment in reflux disease? Am J Gastroenterol 2013;108:1058-1064.

12. Rohof WO, Bennink RJ, Boeckxstaens GE. Proton pump inhibitors reduce the size and acidity of the acid pocket in the stomach. Clin Gastroenterol Hepatol 2014;12:1101-1107, e1.

13. Vo L, Simonian HP, Doma S, Fisher RS, Parkman HP. The effect of rabeprazole on regional gastric acidity and the postprandial cardia/gastrooesophageal junction acid layer in normal subjects: a randomized, doubleblind, placebo-controlled study. Aliment Pharmacol Ther 2005;21:13211330 .

14. Kinoshita Y, Ishimura N, Ishihara S. Management of GERD: are potassium-competitive acid blockers superior to proton pump inhibitors? Am J Gastroenterol 2018;113:1417-1419.

15. Otake K, Sakurai Y, Nishida H, et al. Characteristics of the novel potassium-competitive acid blocker vonoprazan fumarate (TAK-438). Adv Ther 2016;33:1140-1157.

16. Sakurai Y, Mori Y, Okamoto H, et al. Acid-inhibitory effects of vonoprazan $20 \mathrm{mg}$ compared with esomeprazole $20 \mathrm{mg}$ or rabeprazole $10 \mathrm{mg}$ in healthy adult male subjects--a randomised open-label cross-over study. Aliment Pharmacol Ther 2015;42:719-730.

17. Boecxstaens V, Bisschops R, Blondeau K, et al. Modulation of the postprandial acid and bile pockets at the gastro-oesophageal junction by drugs that affect gastric motility. Aliment Pharmacol Ther 2011;33:1370-1377.

18. Wu J, Liu D, Feng C, et al. The characteristics of postprandial proximal gastric acid pocket in gastroesophageal reflux disease. Med Sci Monit 2018;24:170-176.

19. Hila A, Bouali H, Xue S, Knuff D, Castell DO. Postprandial stomach contents have multiple acid layers. J Clin Gastroenterol 2006;40:612-617.

20. Moonen A, Aguilera-Lizarraga J, Bisschops R, Moonen P, Tack J, Boeckxstaens GE. 24-hour multi-pH recording of the postprandial acid pocket and the nocturnal acid distribution at the esophagogastric junction in healthy volunteers. Neurogastroenterol Motil 2019;31:e13694.

21. Beaumont H, Bennink RJ, de Jong J, Boeckxstaens GE. The position of the acid pocket as a major risk factor for acidic reflux in healthy subjects and patients with GORD. Gut 2010;59:441-451.

22. Clarke AT, Wirz AA, Seenan JP, Manning JJ, Gillen D, McColl KE. Paradox of gastric cardia: it becomes more acidic following meals while the rest of stomach becomes less acidic. Gut 2009;58:904-909.

23. Ohara S, Furuta K, Adachi K, et al. Radially asymmetric gastroesophageal acid reflux in the distal esophagus: examinations with novel $\mathrm{pH}$ sensor catheter equipped with $8 \mathrm{pH}$ sensors. J Gastroenterol 2012;47:12211227.

24. Fukuda N, Ishimura N, Okada M, et al. Mucosal breaks show same circumferential distribution in majority of patients with recurrent reflux esophagitis. Endosc Int Open 2017;5:E214-E221.

25. Katsube T, Adachi K, Furuta K, et al. Difference in localization of esophageal mucosal breaks among grades of esophagitis. J Gastroenterol Hepatol 2006;21:1656-1659.

26. Mitchell DR, Derakhshan MH, Wirz AA, et al. The gastric acid pocket is attenuated in H. pylori infected subjects. Gut 2017;66:1555-1562.

27. Raghunath A, Hungin AP, Wooff D, Childs S. Prevalence of Helicobacter pylori in patients with gastro-oesophageal reflux disease: systematic review. BMJ 2003;326:737.

28. Ishimura $\mathrm{N}$, Owada $\mathrm{Y}$, Aimi $\mathrm{M}$, et al. No increase in gastric acid secretion in healthy Japanese over the past two decades. J Gastroenterol 2015;50:844-852.

29. Iijima K, Koike T, Abe Y, Ohara S, Nakaya N, Shimosegawa T. Time series analysis of gastric acid secretion over a 20 -year period in normal Japanese men. J Gastroenterol 2015;50:853-861.

30. Clarke AT, Wirz AA, Manning JJ, Ballantyne SA, Alcorn DJ, McColl $\mathrm{KE}$. Severe reflux disease is associated with an enlarged unbuffered proximal gastric acid pocket. Gut 2008;57:292-297.

31. Yadlapati R, Vaezi MF, Vela MF, et al. Management options for patients with GERD and persistent symptoms on proton pump inhibitors: recommendations from an expert panel. Am J Gastroenterol 2018;113:980986.

32. Oshima T, Arai E, Taki M, et al. Randomised clinical trial: vonoprazan versus lansoprazole for the initial relief of heartburn in patients with erosive oesophagitis. Aliment Pharmacol Ther 2019;49:140-146.

33. Vaezi MF, Yang YX, Howden CW. Complications of proton pump inhibitor therapy. Gastroenterology 2017;153:35-48.

34. Umezawa M, Kawami N, Hoshino S, et al. Efficacy of on-demand therapy using 20-mg vonoprazan for mild reflux esophagitis. Digestion 2018;97:309-315. 